\title{
Intensity of soil transmitted helminths in relation to soil profile in selected public schools in ibadan metropolis
}

\begin{abstract}
Pre-school and school age children are in the high risk category for Soil Transmitted Helminths (STH) infections. This study was designed to investigate soil characteristics and patters of STH intensity in soil samples obtained from selected primary schools around Ibadan. A total of 480 soil samples were collected between November 2014 and June 2015 from three different locations and examined for parasite types and intensity. The spatial patterns of parasite intensity in relation to soil physiochemical parameters were determined. Parasite types found included Hookworm, Strongyloides and Ascaris. A total of 340 (70.8\%) of the soil samples collected had at least one parasite type. The parasite count across the

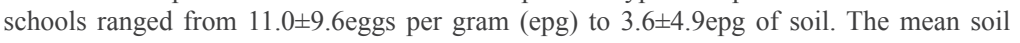
temperature and moisture content were $23.8 \pm 0.72{ }^{\circ} \mathrm{C}$ and $8.5 \pm 6.5 \%$ respectively. There was a negative correlation between soil temperature and parasite intensity $(\mathrm{r}=-0.3)$ while a positive correlation occurred between parasite intensity and moisture content $(\mathrm{r}=0.3)$. The presence of viable STHs eggs/ larvae in soil suggests possible active transmission and high rate of exposure to infective agents among the school children. There is a need for health education on risk associated with STH infection in the environment.
\end{abstract}

Keywords: soil transmitted helminths, physiochemical, parasite intensity, soil profile, viable
Special Issue - 2018

Adesola A Hassan, David A Oyebamiji
Department of Zoology, University of Ibadan, Nigeria

Correspondence: David A Oyebamiji, Parasitology Unit, Department of Zoology, Faculty of Science, University of Ibadan, Nigeria, Tel +23438035783607 ,

Email doyebamiji6880@stu.ui.edu.ng

Received: January 25, 2018 | Published: September 19,2018

\section{Introduction}

Sub-Saharan Africa is one of the regions with the greatest burden of Soil transmitted helminth. ${ }^{1,2}$ The associated diseases are more prevalent in tropical settings among the rural populations than in other populations in the same region. ${ }^{3}$ Available evidence indicates that almost all excreted pathogens can survive in soil for a sufficient length of time and thus pose potential risks to man and animals. ${ }^{4}$ Generally, STH infections are associated with poverty, lack of sanitation, illiteracy, poverty, poor environmental hygiene, impoverished health and overpopulation. ${ }^{5,6}$ These socio-economic factors abound in most developing countries, Nigeria not an exception. ${ }^{7}$ reported that in Nigeria, a considerable amount of human and animal wastes are discharged into the soil daily leading to the contamination of the soil with STH eggs and larvae. ${ }^{8}$ reported that $62 \%$ of the families of the cohort children disposed of child faeces in open spaces. Human soil contact thus poses a major predisposing factor in transmission of the STH.

There are many abiotic and biotic variables, which may affect parasites in the soil. The survival and development of parasite eggs are dependent on favourable degrees of temperature, moisture, desiccation, $\mathrm{pH}$, soil depth and texture. ${ }^{4,9,10}$ Most activities with respect to STH mapping have been attempted in some African countries. ${ }^{11-13}$ There is a dearth of information on the extent of parasite contamination in soil around Ibadan and Nigeria at large. The control of infection in Nigeria remains relatively inadequate due to lack of reliable data on the geographical distribution of diseases and the population at risk..$^{14,15}$ School children are mostly the high risk population in the communities because they often play with soil and walk around bare-footed, traits also peculiar to pre-school children, it is therefore pertinent to examine the presence of eggs or larvae of STH in soil samples around the school premises and the immediate environments which are subject to run offs during rainfall. Furthermore, $90 \%$ of the investigations carried out on STH were based on faecal samples obtained from participants, while only a few were related to soil samples. Hence the present study investigated soil faecal contamination, soil characteristics and intensity of STHs in public primary schools in Ibadan metropolis and also provide some relevant epidemiological details that may enhance effective intervention planning.

\section{Methods}

\section{Study area and location}

The study was undertaken in selected public primary schools within each of five local government areas; Ibadan South East, North East, Akinyele, North West, and Ibadan North, in the city of Ibadan, Oyo state, south-western part of Nigeria (Figure 1). Each of the school is central to the geographic location of its area. Only one of the schools has a functional toilet facility, while the other four lack functional toilet facility.

\section{Soil sampling}

Sampling survey was conducted between November 2014 and June 2015. A total of 480 soil samples (60 soil samples for each month) were collected from all the sites. 4 soil samples were taken from each of the three sample points (play ground, toilet area and refuse dump site) in each month. Soil sampling was carried out in the morning between $6.00 \mathrm{am}$ and $11.00 \mathrm{am}$, as recommended by. ${ }^{16}$ Approximately $100 \mathrm{~g}$ of soil was collected randomly at a depth of $2-3 \mathrm{~cm}$ according to 
outline giving by ${ }^{17}$ Each sample was placed inside a properly labelled polythene bag and transported to laboratory in the Department of Zoology, University of Ibadan, Nigeria for examination and analysis.

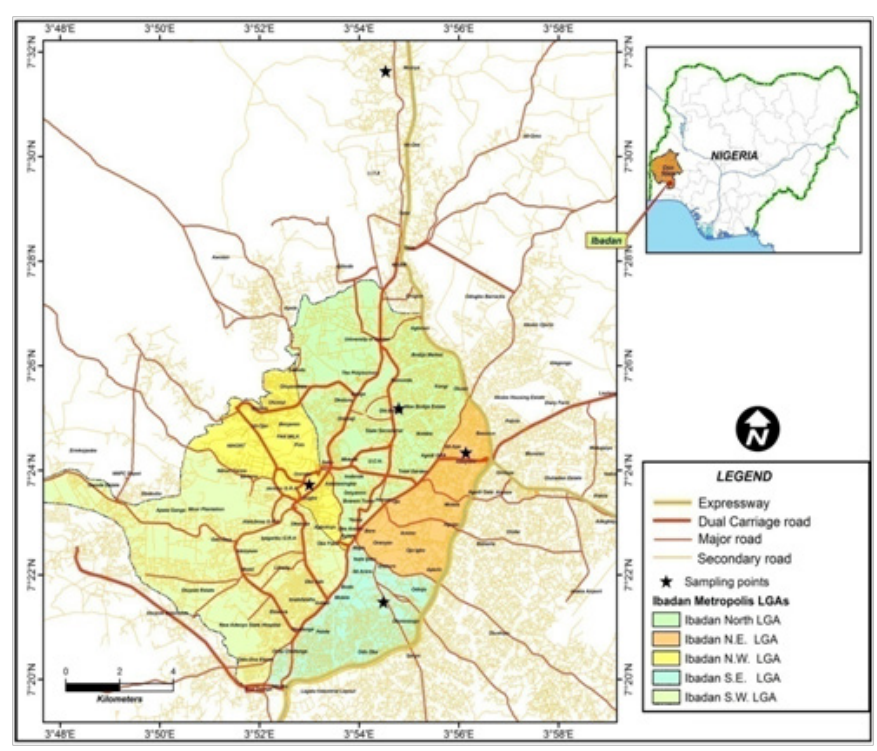

Figure I Map of Ibadan showing the study locations [Saviour's Apostolic Primary School (SAPS) in Ibadan N.W. LGA, Christ Church Mapo School 7 (CCMS7) in Ibadan S.E. LGA, Methodist Primary School II (MPSII) in Ibadan North LGA, Army Children School 8 (ACS8) in Ibadan N.E. LGA and Islamic Mission Primary School II (IMPSII) in Akinyele LGA].

\section{Isolation and Concentration of STH Eggs/ Larvae}

Soil transmitted helminths eggs and larvae were extracted using the modified Cobb's Decanting and Sieving Method ${ }^{18}$ and modified Baermann method. Eggs were identified with the aid of standard guidelines. ${ }^{19}$ The larvae/ova of parasites were identified with reference to Atlas of Medical helminthology and protozoology ${ }^{20}$ and Parasites of man and animal. ${ }^{21}$ The number found were counted and recorded.

\section{Determination of parasite intensity}

Parasite Intensity (total mean egg/larvae) was estimated per gram of soil samples using method described by. ${ }^{10}$

Soil profile determination: Particle size analysis by Hydrometer Method described by ${ }^{22}$ was carried out and Soil composition estimated in percentages using the following equations:

$\%$ clay $=$ corrected hydrometer reading at 7 hours $\mathrm{x} 100$

Weight of sample

$\%$ silt $=$ corrected hydrometer reading at $40 \mathrm{sec} . \times 100$

Weight of sample - \% clay

$\%$ sand $=100 \%-\%$ silt - \% clay

\section{Determination of Physico-chemical parameters of soil sample}

Soil Temperature and $\mathrm{pH}$ values were obtained as described by ${ }^{23}$ using Electrochemistry multimeter CS-C933T (Topac Instrument Inc.).

\section{Soil Moisture Content (\%)}

Twenty grams $\left(\mathrm{W}_{0}\right)$ of soil was weighed into a Petri-dish (of known weight) and dried in oven at $110^{\circ} \mathrm{C}$ for 24 hours, the final constant reading $\left(\mathrm{W}_{1}\right)$ was obtained and recorded. Soil moisture content by ${ }^{21}$ and expressed in percentages.

\section{Mapping intensity and risk of spread}

The GPS data was converted to Easting and Northing points, and integrated to an image using Geographic Information Systems software (ArcGIS 9.3 software). The parasite load at each coordinate point was used in relation to the soil characteristics to map the spread using Independent Distance Weighted (IDW) method of interpolation.

\section{Statistical analysis}

Data were analyzed using Statistical Package for Social Sciences (SPSS) version 17 and Microsoft Excel Spread Sheet 2007. Correlation between each transmission index and soil contamination, risk of infection and the physiochemical parameters of soil samples from the different sites were determined. Chi square $\left(\chi^{2}\right)$ was employed to determine significant differences between variables. ${ }^{23}$

\section{Results}

Parasite types and frequency of occurrence: Out of the 480 soil samples, $70.8 \%$ contained parasites. The types and species specific intensity of parasites encountered are: Ova of Ascaris 142 (5.3\%), larvae and adult Strongyloides 597 (22.3\%) and larvae of hookworm 1940 (72.4\%). Hookworm occurred most followed by Strongyloides and Ascaris. Similar trend was found in each of sampling locations.

\section{Intensity in relation to sampling locations:}

The highest parasite intensity was found in IMPSII, followed by CCMS7, ACS, SAPS, and the least count was recorded for MPSII (Table 1).

Table I Parasites abundance in sampled areas

\begin{tabular}{lllll}
\hline $\begin{array}{l}\text { Study } \\
\text { location }\end{array}$ & \multicolumn{2}{l}{ Parasite species counts } & \multicolumn{2}{l}{$\begin{array}{l}\text { Total count } \\
\text { (Freq of } \\
\text { occurrence) }\end{array}$} \\
\hline & Hookworm & Strongyloides & Ascaris & \\
\hline SAPS & 269 & 78 & 3 & $350(13.1 \%)$ \\
CCMS7 & 392 & 105 & 19 & $516(19.3 \%)$ \\
MPSII & 246 & 75 & 27 & $348(13 \%)$ \\
ACS8 & 276 & 94 & 31 & $401(15 \%)$ \\
IMPSII & 757 & 245 & 62 & $1064(39.7 \%)$ \\
$\begin{array}{l}\text { Total parasite } \\
\text { count (freq of } \\
\text { occurrence \%) }\end{array}$ & $(72.4 \%)$ & $597(22.3 \%)$ & 142 & 2679 \\
\hline
\end{tabular}

\section{Intensity of parasite in each sampling site}

Refuse dump site had the highest mean parasite intensity $7.08 \pm 7.55$, followed by toilet area with a mean parasite intensity of $5.48 \pm 6.78$, while the least intensity was recorded for playground, $4.19 \pm 5.93$. There was a significant difference $(\mathrm{P}<0.05)$ in the mean intensity of STH across the sites. 


\section{Mean intensity of parasites in relation to soil types}

Four soil types (Sandy, Sandy Loamy, Sandy Clay Loamy and Clay) soil types were encountered during the study. Sandy loamy soil had the highest mean parasite intensity of $2.73 \pm 4.71$ followed by sandy loamy clay soil with a mean intensity of $2.72 \pm 4.05$; sandy soil had a mean parasite intensity of $2.09 \pm 3.68$, while clay soil type had the least mean intensity of $1.02 \pm 1.40$. There was statistical significant difference $(\mathrm{P}<0.05)$ between soil type and parasite intensity across the group.

A.

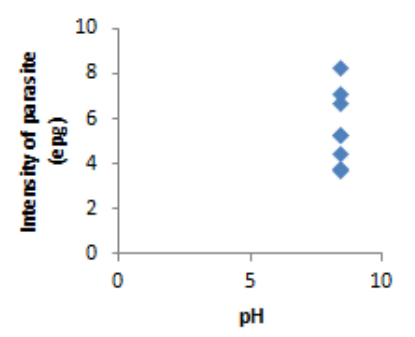

C.

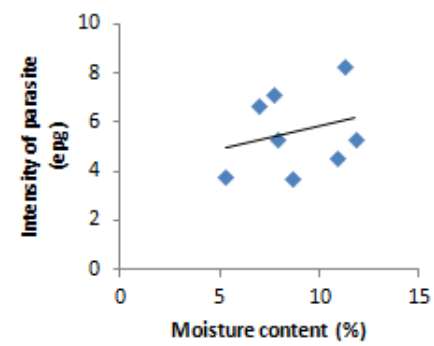

Figure 2 Parasite intensity in relation to physicochemical parameters.

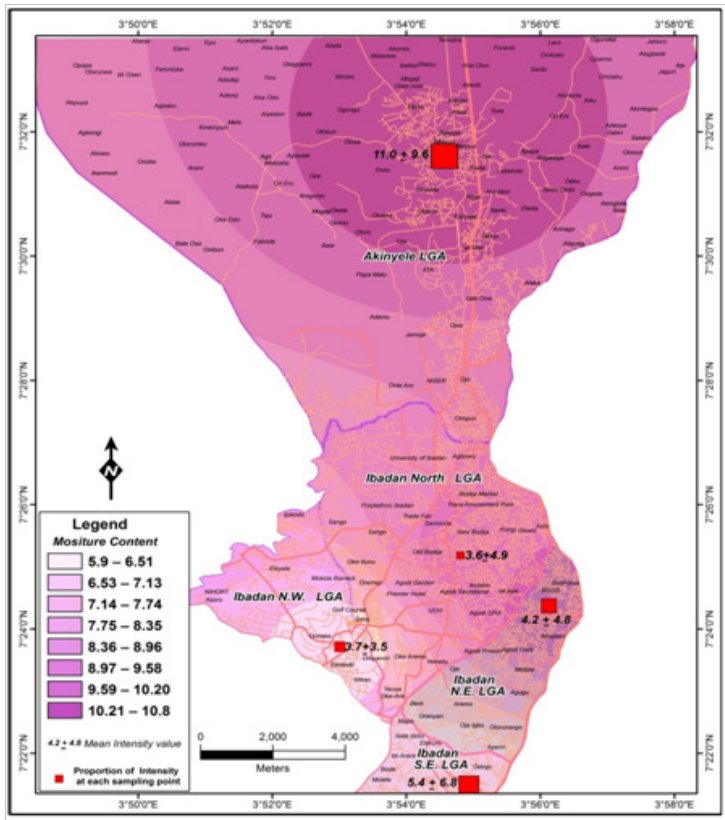

Figure 3 Parasite intensity in respect to moisture content.

\section{Variation in physico-chemical parameters in relation to parasite intensity}

Mean Temperature, Moisture content and $\mathrm{pH}$ values were $23.8^{\circ} \mathrm{C} \pm$ $0.72329,8.5 \pm 6.5$ and $8.4 \pm 0.4$. Figure 2 shows a negative correlation $(\mathrm{r}=-0.3)$ between temperature and parasite intensity and a moderate correlation $(\mathrm{r}=0.3)$ between the moisture content and intensity. No correlation between $\mathrm{pH}$ and intensity. Spatial distribution patterns of parasite intensity for the significant soil parameters are shown in Figure 3 \& Figure 4. Highest intensity of $11 \pm 9.6 \mathrm{epg}$ was found in Akinyele where the highest moisture content of $10.8 \%$ and lowest temperature were recorded.
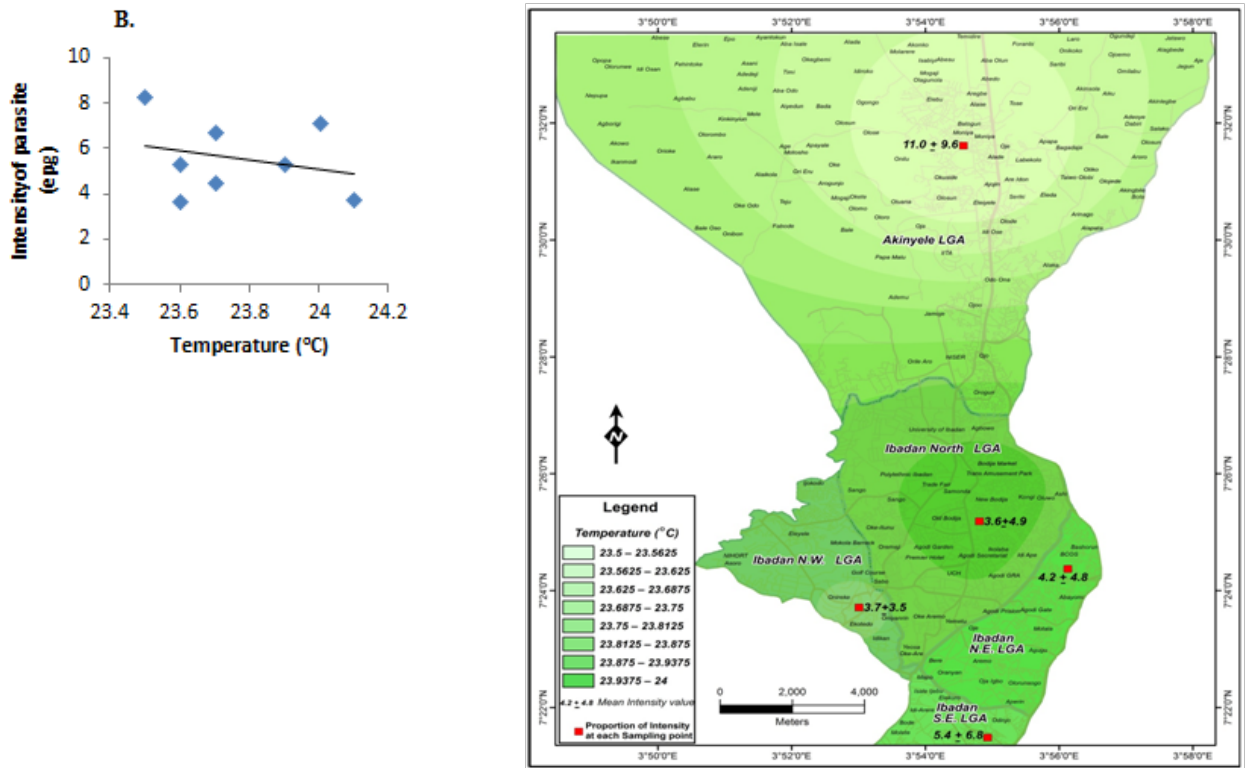

Figure 4 Parasite intensity in relation to temperature.

\section{Discussion}

The contamination of the soil with STH eggs and larvae according to ${ }^{6}$ are common in the developing countries. Most STH infections are transmitted through the faecal-oral route. ${ }^{24}$ reported that soil is the most direct indicator of risk. The observation of the present study in line with earlier observation reported by ${ }^{25}$ showed seventy or more percent of the soil samples collected in school premises were contaminated with STH eggs/larvae, supportive of a significant high level of soil contamination with faeces. In the schools where functional toilets were lacking or remained under lock and key, pupils naturally defecated around refuse dump sites located close to the toilets. This could have accounted for the high parasite load that was observed in the refuse dump sites compared to playground and toilet areas which are however exposed locations. Two other sampling locations with functional toilets had refuse dump sites also located close to the toilets, but the higher intensity observed in one school compared to observations made at the other might have been due to the seclusive location of refuse dump site and toilet directly behind pupils' class rooms, which more or less provided a secluded open defecation sites for the pupils. This open communal contamination of soil with infected faeces thus pose serious risk to other uninfected persons and also serve as a source of re-infection particularly in the event of rainfall run-offs. Commonly, children practicing habitual 
or occasional open defecation had almost twice the odd of being parasitized with more than one STH species. ${ }^{10,17}$ Also showed that children living in households lacking toilets or latrines had increased odds of hookworm infection and since most of these students spend at least half of their time in school without toilet facility, they are therefore at high risk of contracting infection. It was observed that among the three study sites (toilet area, play-ground and refuse dump site), the playground had the highest intensity where higher elevation favoured the dump site thus facilitated easy water runoff with a likely chance of carrying contaminated soil with it. During this present study it was also observed that where schools lack perimeter fence, children and even adults around the school environment had access to the school compound after school hours and possibly defecate in the soil thereby contaminating the school environment with helminth eggs. The trend of the parasite distribution observed might have probably been due to the unique characteristics of the soil. Sandy-loamy soil type with more than $75 \%$ fine sand and less than $15 \%$ of clay which allow for well-aeration, non adhesion, proper draining with an additional presence of silt that contain microscopic and barely particles that provide optimal condition for parasites development could explain the high parasite intensity in soil. ${ }^{16,26}$ On the other hand, clay soil type had the least parasite count compared to other soil types, similar findings were reported by. ${ }^{27,26}$ The low parasite count may be due to low water permeabilty and the small interstitial pores associated with this soil type. In the present study, it was observed that more hookworm larvae were found in the sandy loamy soil type compare to other soil types, in line with observations by. ${ }^{27}$ These previous report confirmed that, hookworm prevalence was significantly associated with well drained sandy soil type (clay content less than $15 \%$ ). The prevalent parasitic forms found in this study tolerated the basic soil conditions (a pH of $8.3 \pm 0.36$ ), which is in line with other reports that helminth eggs are said to tolerate a wide range of $\mathrm{pH}$. The World Health Organisation (2004) reported that hookworm and other STH tolerate $\mathrm{pH}$ range of 4.6-9.4 and would still be able to hatch and infect hosts. Hookworm eggs are very resistant in the environment and can survive in the soil for a period of 3 weeks and still remain infective,$^{10}$ this can explain the high abundance of hookworm in the sampled areas. Intensity of infection was high throughout the sampling period with the highest parasites counts per gram of soil were recorded in June when the moisture content was about $17.5 \%$ and fell within the optimum range (10 - 33.8\%) of required moisture content. In spite of the onset of dry season in November, the soil still supported occurrence of parasite showing $90 \%$ contamination rate on soil samples and intensity of 6.58 eggs/gm of soil. The higher contamination rate in the rainy season correlates with the findings from other studies. ${ }^{16,23,28} \mathrm{~A}$ high number of embryonated helminth eggs, containing larvae were identified during the study, suggesting that the environmental conditions in the study area allowed for further development of the voided ova making them retain viability and available for transmission year round. This is evidence of active transmission going on with higher chances of getting infected among the younger age category. The mean intensity and moisture content was highest at Akinyele while other areas with reduced moisture content had reduced intensity. This implies that the higher the moisture content, the higher the intensity of parasites because moisture content aid the survivability of parasites. ${ }^{11}$ On the other hand, temperature and intensity obtained gave a reverse scenario (Figure 4). Akinyele had the least temperature (23.6\%) yet still retains the highest intensity. This showed that the lower the temperature, the higher the number of parasites in the soil samples obtained in the area.

\section{Conclusion}

The risk of infection with Hookworm, Ascaris, and Strongyloides detected in all the schools suggests that each student in all these schools was susceptible to acquiring these parasites.

The extent of spread of parasite in this study poses a threat to the students in these areas. The predictive spatial spread of the infection in the areas observed in this study will assist in planning targeted control and intervention programmes. Trichuris spp, an important member of the STHs was not found during this present study. Further investigation to monitor prevailing conditions for the development and survival of Trichuris in the soil is significant.

\section{Declarations}

We declare that this is an original work, it has not been previously published or accepted for publication in any journal and has not been submitted to any other journal for consideration and publication.

\section{Acknowledgements}

Special appreciation goes to the Headmasters of the schools involved in the study for granting to obtain soil sample from the school premises. Mr. Joseph of the Department of Geography, University of Ibadan for production of the maps and also the technical staff of the Department of Zoology for assistance rendered during the laboratory analysis.

\section{Author's contributions}

Adesola A. Hassan and David A. Oyebamiji designed the experiment, wrote and proofread the manuscript for publication. David A. Oyebamiji went to the field and did the data analysis.

\section{Conflict interests}

None.

\section{References}

1. De Silva NRS, Brooker PJ, Hotez A, et al. Soil-Transmitted Helminth Infections: Updating the Global Picture. Trends Parasitol. 2003;19(12):547-561

2. Pullan RL, Smith JL, Jasrasaria R, et al. Global numbers of infection and disease burden of soil transmitted helminth infections in 2010. Parasit Vectors. 2014;7(1):37

3. Rubinsky EG, Hirata CE, Yamamoto JH, et al. Human toxocariasis:diagnosis, worldwide seroprevalences and clinical expression of the systemic and ocular forms. Ann Trop Med Parasitol. 2000;104(1):3-23.

4. WHO. Prevention and control of schistosomiasis and soil transmitted helminthiasis. Parasitol Int. 2004;53(2):103-113.

5. Ekundayo OJ, Aliyu MH, Jolly PE. A review of intestinal helminthiasis in Nigeria and the need for school based intervention. J Rural Trop Publ Heal. 2007;6: 33-39.

6. Ojurongbe O. Terminating the neglect of neglected tropical diseases in Africa. J of Medical and Microbiological Diagnosis. 2013;2(2):1000.

7. Ojurongbe O, Oyesiji KF, Ojo JA, et al. Soil transmitted helminth infections among primary school children in Ile-Ife Southwest, Nigeria: A cross-sectional study. International Res J Med Med Sci. 2014;2(1):610 . 
8. Roy M, Shohamy D, Wager TD. Ventromedial prefrontal-subcortical systems and the generation of affective meaning. Trends $\operatorname{Cog}$ Sci. 2012;16(3):147-156.

9. Amadi EC, Uttah EC. Bionomics of Geohelminth Nematodes in Contaminated Foci in parts of Abua Communities, Niger Delta, Nigeria (A). J Sci Enviromental Management. 2010;14(2):61-64.

10. Paller VGV, De Chavez ERC. Toxocara (Nematoda: Ascaridida) and Other Soil-Transmitted Helminth Eggs Contaminating Soils in Selected Urban and Rural Areas in the Philippines. Sci W J. 2014;386:23-26.

11. Hotez PJ, De Silva N, Brooker S, et al. Soil transmitted helminth infections: the nature, causes and burden of the condition. (Bethesda, Maryland, Disease Control Priorities Project: Fogarty International Centre, National Institutes of Health); 2003.

12. Brooker S, Kabatereine NB, Smith JL, et al. An updated atlas of human helminth infections: the example of East Africa. Int $J$ Health Geogr. 2009;8:42.

13. Pullan RL, Gething PW, Smith JL, et al. Spatial modelling of soiltransmitted helminth infections in Kenya: a disease control planning tool PLoS Negl Trop Dis. 2011;5(2):e958.

14. Nock IH, Duniya D, Galadima M. Geohelminth eggs in the soil and stool of pupils of some primary schools in Samaru, Zaria, Nigeria. Nig $J$ Parasitol. 2007;24:115-122.

15. Ogbolu DO, Terry Alli OA, Amoo AOJ, et al. High level of parasitic contamination of soil sampled in Ibadan metropolis. Afr J Med Sci. 2011;40(4):321-325.

16. Nwoke, EU, Ibiam GA, Odikamnoro OO, et al. Examination of soil samples for the incidence of geohelminth parasites in Ebonyi northcentral area of Ebonyi State, south-east of Nigeria. Arch Appl Sci Res. 2013;5(6):41-48.

17. Cobb N A. Estimating the nematode population of the soil. Agric Téch Bur P1 Ind. 1920;1:19-24.

18. Cheesbrough M. District laboratory practice in tropical countries Cambridge University Press, 2000;209(211):212-215.

19. Chiodini PL, Moody AH, MenserDW. Atlas of Medical Helminthology and Protozoology. 4th ed. 2003.

20. Otubanjo O. Human intestinal nematode II: Hookworm and hookworm diseases. Parasites of man and animals. Concept publication Limited, 2013;465-481.
21. Olabiyi TI, Olayiwola AO, Oyediran GO. Influence of soil texture on distribution of phytonematodes in the South Western Virginia. World $J$ Agricultural Sci. 2009;5(5):557-560.

22. Bouyoucos GJ. Hydrometer method improved for making particle size analysis of soils.Agro J. 1961;54:464-465.

23. Ogbolu DO, Terry Alli OA, Amoo AOJ, et al. High level of parasitic contamination of soil sampled in Ibadan metropolis. Afr J Med Med Sci. 2011;40(4): 321-325.

24. Uga S, Nagnaen W, Chongsuvivatwong V. Contamination of soil with parasite eggs and oocysts in southern Thailand. Southeast Asian J Trop Med Publ Heal. 1997;28(3):14-17.

25. Nock IH, Duniya D, Galadima M. Geohelminth eggs in the soil and stool of pupils of some primary schools in Samaru, Zaria, Nigeria. Nig J Parasitol. 2007;24:115-122

26. Saathoff E, Olsen A, Sharp B, Kvalsvig JD, et al. Ecological coviariates of hookworm infection and reinfection in rural Kwazulu-Natal/South Africa: A Geographical Information System-Based study. Am J Trop Med Hyg. 2005;72(4):384-391.

27. Mabaso M L, Appleton CC, Hughes JC. et al. The effect of soil type and climate on hookworm (Necator americanus) distribution in KwaZuluNatal, South Africa. Trop Med Intl Hlt. 2003;8(8):722-727.

28. Rai K, Uga S, Ono K, et al. Contamination of soil with helminth parasite eggs in Nepal. Southeast Asian J Trop Med Publ Health. 2000;31(2):388393

29. Ekpo UF, Odoemene SN, Mafiana CF, et al. Helminthiasis and hygiene conditions of schools in Ikenne, Ogun State, Nigeria. PLoS Negl Trop Dis. 2008;2(1):e146.

30. Gabrie JA, Rueda MM, Canales M, et al. School hygiene and deworming are protective factors for reduced transmission of soil-transmitted helminthes among school children in Honduras. Parasite Vectors. 2014;7:354.

31. Knopp S, Mgeni AF, Khamis IS, et al. Diagnosis of soil-transmitted helminths in the era of preventive chemotherapy: effect of multiple stool sampling and use of different diagnostic techniques. PLoS Negl Trop Dis. 2008;2(11):e331. 